\title{
Firm Value, Diversified Capital Assets, and Credit Risk: Towards a Theory of Default Correlation
}

\author{
Lars Grüne* $\quad$ Willi Semmler ${ }^{\dagger} \quad$ Lucas Bernard ${ }^{\ddagger}$
}

November 4, 2007

\begin{abstract}
Following the lead of Merton (1974), recent research has focused on the relationship of credit risk to firm value. Although this has usually been done for a single firm, the growth of structured finance, which necessarily involves the correlation between included securities, has spurred interest in the connection between credit-default risk and the dependencies and cross-correlations arising in families of firms. Previous work by Grüne and Semmler (2005), focusing on a single firm, has shown that firm-value models, incorporating company-specific endogenous risk premia, imply that exposure to risk does impact asset value. In this paper, we extend these results to study the effects of random shocks to diversified capital assets wherein the shocks are correlated to varying degrees. Thus, we construct a framework within which the effects of correlated shocks to capital assets can be related to the probability of default for the company. The dynamic decision problem of maximizing the present value of a firm faced with stochastic shocks is solved using numerical techniques. Further, the impact of varying dependency structures on the over-all default rate is also explored.
\end{abstract}

\footnotetext{
*Mathematical Institute, University of Bayreuth, Germany; e-mail: Lars.Gruene@unibayreuth.de

${ }^{\dagger}$ Center for Empirical Macroeconomics, Bielefeld, Germany, The Bernard Schwartz Center for Economic Policy Analysis, and The New School for Social Research, New York, NY; email: SemmlerW@newschool.edu

$\ddagger$ The New School for Social Research, New York, NY and Long Island University, Brooklyn, NY; email: LBernard@LIU.edu
} 


\section{Introduction}

There is a long tradition of deriving security prices, e.g., stocks and bonds, from the value of a company's assets. The general background literature goes back to Modigliani and Miller (1958), Black and Scholes (1973), and Merton (1974) where it is presumed that the asset value of the company is exogenously given by a Brownian motion at the time the company's debt is priced. This is usually done by using the classic balance sheet equivalency: $V=S+B$ where $V$ is the asset value, $S$ is the value of stocks, and $B$ is the value of bonds. Furthermore, when short-term interest rates are given, one can derive the risk structure of interest rates. ${ }^{1}$

Recent advances in the development of financial instruments have led to the recognition that the mechanisms by which companies borrow and, thus, generate credit risk, are quite complex. When combined together, a completely new set of phenomena is created, e.g., default frequency. The rise of CDOs and other structured financial products, as well as recent credit market events, have greatly increased the interest in the correlation between default events occurring beneath a single umbrella. On the one hand, the grouping together of a number of entities creates an even more complex entity, on the other, it also allows for the use of macroscopic analysis, e.g., macro-factors underlying probabilities. ${ }^{2}$ It is largely this observation that has given rise to modern risk management, which is concerned with the evaluation and control of credit risk. However, we feel that there is still reason to examine some of the fundamental processes which must lie beneath the global phenomena.

In this paper, we focus on evaluating a company's capital assets and credit risk in the context of a production oriented asset pricing model. ${ }^{3}$ In our paper, we consider the evaluation of the default risk of a company by solving a debt control problem treated as a dynamic decision problem. Using this construction, the solution of the dynamic decision problem gives us the company's asset value. We then extend this method to include multiple capital assets which are subject to random shocks. In this way, we examine how the default probability might be related to the correlation of shocks to the different fractions of a company's capital assets. Much as volatility has come to be the quoted variable in derivatives analysis, so correlation is becoming the quoted variable in structured finance.

Following the aforementioned tradition in asset pricing, in our first step, we show how the asset value of a company depends upon the default risk of the company. This will, in turn, be defined by the creditworthiness of the company.

\footnotetext{
${ }^{1}$ For details see Merton (1974).

2 This is similar to the way in which the properties of temperature and pressure allow one to deal with the fundamentally chaotic movement of individual atoms; so too, certain broad statistical measures may allow for a systematic treatment of collections of risky securities without a complete understanding of the underlying processes.

${ }^{3}$ Some preliminary thoughts on the relationship of credit and a firms' capital assets can be found in Keynes (1967, ch. 12).
} 
We presume that companies pursue dynamic investment decisions and will show that the key to the impact of debt finance on the company's asset value is its impact on credit cost. Specifically, we will demonstrate that default risk varies with the internal decisions made with respect to the use of capital assets. Company behavior under external financial constraints has been studied in many papers. ${ }^{4}$ In this paper we study how external finance, e.g., default premia paid on bonds, impact investment and company value, in particular, the probability of default for a firm possessing diverse capital assets.

The above mentioned literature on asset pricing has not sufficiently considered the impact of default premia on the value of companies' assets. It also tends to disregard the attempts that managers may make to internally hedge their company's investments. Usually it is assumed that a company can undertake investment by borrowing from the capital markets at an ex-ante capital cost up to the point where the discounted pay-off is equal to the present value of the company. Taking this as a benchmark case, we consider the pricing of a company's assets in the cases where the company faces borrowing constraints or when the company faces an external finance premium due to collateralized borrowing. The external finance premium is, in this literature, often interpreted as a default premium reflecting company-specific default risk. It is the company specific default risk that will give rise to a risk-caused endogenous credit cost and thus an endogenously determined risk structure of interest rates in the sense of Merton (1974).

In the second step, we argue that the problem of managing a company's risk profile, as defined in the company's bond pricing, is essentially a problem of the optimal control of company debt, the dynamics and correlation between the diversified elements of its capital stock, and its asset value. Here too, default risk and default premia, in contrast to many other recent models, will be endogenized and made state dependent, thus allowing us to treat the overall default rate of the company's bonds from the input side, i.e., that arising from the diversified capital assets.

Here, our second step is undertaken in a stochastic environment. In particular, we are interested in the relationship between the diversification present in a company's capital assets and the resulting probability of default. In the finance literature, it is already well recognized that the value of stocks may not be independent of the valuation of the firm's debt; for example see Hanke (2003, ch. 2). An important issue in computing the asset value of a company is the optimization problem of that company. Consumption-based asset pricing theory would argue that the objective of the company is to deliver a stream of dividends for the equity holder. The optimization problem of the company would then be to maximize the present value of dividends to the share holders. We show that with respect to debt-financed investment, one should be interested in the asset value of the company and not solely in the equity value of the company relevant for the share holders. The work on pricing corporate

\footnotetext{
${ }^{4}$ See Gaskins (1971), Judd and Petersen (1986), Gertler and Gilchrist (1994), and other literature cited.
} 
liability has largely taken this tone since Merton (1974) and numerous empirical approaches have been pursued to infer, from time series data on equity values, the asset value of a company. ${ }^{5}$

We also note that if we take the maximization of the equity value for the share holders as the optimization problem, it is obvious - since endogenous credit costs reduce the net income of the company before dividends are paid that the equity value of the company will be affected by state-dependent default premia.

What is important in our formulation of the optimization problem is that the asset value of the company and the default risk will be affected not only by the sequence of optimal investment decisions (size of investment and allocation of resources) of a company, but that the default premia are impacted by the correlation of shocks to the diversified capital assets. We are dealing with a complicated constrained optimization problem in a stochastic environment; its solution will require advanced numerical methods.

As to our solution method, we note that these rather complex models cannot be solved analytically. We will make use of numerical dynamic programming for the deterministic case and a set-oriented algorithm to solve the different model variants in the stochastic case. These methods are well suited to the study of problems wherein companies face imperfect capital markets, where the risk premia are endogenized, and where there might be correlated risk to the company's capital assets. ${ }^{6}$

The remainder of the paper is organized as follows: Section 2 discusses the literature, while Section 3 treats some issues of default premia and asset pricing. Section 4 introduces the basic dynamic asset pricing model and sets forth the stochastic version for diversified capital assets. Section 5 discusses the numerical procedures. ${ }^{7}$ Section 6 reports the detailed results from our numerical study on the different variants of the model. Section 7 concludes the paper.

\section{Related Literature}

Clearly, default risk is of great interest not only to bond holders, but to owners of equity as well. As residual claimants, they are strongly influenced by bond defaults. However, though simple to state, it is not immediately obvious either how to measure default risk or how to model it. On the one hand, the causes of default risk, from loss of competitiveness, to a weak economy, to misperceptions of risk and return, to corporate mismanagement, are many and often hidden within the company. As outlined in Crouhy, Galai, and Mark (2000) credit risk may also become manifest in a multitude of ways. From downgrades,

\footnotetext{
${ }^{5}$ See, for example, Duan, Gauthier, Simonato and Zaanoun (2002). There, a survey of empirical methods is given on how to estimate the asset value of the firm using a time series analysis of its equity value.

${ }^{6}$ A stochastic version of such a dynamic programming algorithm is used in Grüne and Semmler $(2004,2007)$ where a consumption based asset pricing model is solved.

${ }^{7}$ More details on the numerical methods can be found in the papers by Grüne and Grüne \& Semmler listed in the references.
} 
actual defaults, and other company-specific factors to changes in market indices, general economic factors, and interest, exchange, and unemployment rates, both the causes and the manifestations of changes in credit conditions are complex. Nonetheless, ultimately, the issue of default risk boils down to the question of: "Is there sufficient asset value in the company to pay the obligations due?"

The problem of how to measure and manage default risk, in particular that associated with corporations is as old as the concept of the company itself. Prior to the 1950s, most techniques focused on traditional accounting and financial statement-analysis methods. Franco Modigliani was the first to place the problem within the theoretical context now recognizable as modern finance. Along with coauthor Merton Miller, Franco Modigliani (1958) rigorously proposed scaffolding for the exploration of the relationship between a company's market value and its debt and equity financing. An explicit equivalency linking the value of a company to its financial structure, expressed in terms of bonds, equity, and derivative securities based on these was established.

The 1960s and 1970s saw an explosive growth in the use of equity options culminating with the founding of the Chicago Board Options Exchange, CBOE, in 1973. The ready existence of a liquid market for derivative securities allowed for new types of analysis. Black and Scholes (1973) realized that what market makers actually do is to take risk-neutral positions in the contracts they deal with and make their money off the bid-ask spread. ${ }^{8}$ Therefore, the price of an option is determined by the costs involved in creating a risk-neutral portfolio. Under this paradigm, it becomes clear that it is stock-price volatility that determines the prices for both puts and calls. In fact, for this reason, traders are just as likely to quote volatility as they are to quote price.

Merton (1974), one year later, utilized this same methodology, treating the value of corporate debt, from the perspective of derivative pricing, in order to study the risk structure of corporate bonds. The Modigliani-Miller (1958) and Merton (1974) results follow from the proposition that the capital structure does not affect the company's asset value. Although, as shown in recent papers, applying Black-Scholes and option pricing, the stock price of the company can be impacted by the capital structure, yet the asset value, which is split up into stocks and bonds, is independent of the capital structure. ${ }^{9}$ Those results are, however, obtained by assuming an exogenous stochastic process, a Brownian motion, for the asset value, which does not originate, as we will argue later, from the solution of a dynamic decision problem of a company acting under constraints. In other words, because of the complexity of the underlying company's value-debt dynamics, it is tempting to build models that do not depend upon them, i.e., to make no attempt to offer a causal explanation for the phenomena.

Credit spread models, for example, treat the problem by considering the

\footnotetext{
${ }^{8}$ In other words, they guarantee a liquid market by maintaining fully hedged positions which they continually adjust to reflect market movements and sales of both sides of their portfolios.

${ }^{9}$ See Hanke (2003).
} 
spread between the interest rate on defaultable debt and that of similar maturity risk-free debt. The idea here is that the reason for the spread is that bond purchasers need to be compensated for the risk present in the former and that this will yield information about the probability of default. Jonkhurt's (1979) paper is one of the first to discuss the credit spread approach, while Hull and White (2000) have a more recent treatment. Another popular approach is the intensity model. Whereas the company-value method attempts to link default frequency to fundamental processes related to the financial structure of a company, an intensity model only seeks to describe the statistical characteristics of these events. Thus, like the credit spread approach, it offers little explanation of the fundamental default process. Madan and Unal (1998) use intensity-based methods in their paper and Duffie and Singleton (1997) develop the topic within the context of factor models.

The rise of structured financial products, e.g., CDOs, wherein collections of risky products are grouped together, has greatly increased the interest in default correlation models. Through the use of copula functions and other methods, it is possible to relate the default dependency internal to complex products to a generalized correlation variable. This framework also allows for the discussion of correlated defaults within the context of both intensity and company value models. Douglas Lucas' (1995) paper is one of the first to explicitly discuss the topic, whereas Schönbucher (2001) and Embrechts, Lindskog, and McNeil (2003) present more contemporary treatments. Das and Duffie (2005) present evidence on how default events definitely correlate to a greater degree than had been thought. In contrast, our study is interested in correlations between "input" variables, i.e., stochastic shocks to different elements of a company's capital assets and how those shocks ultimately influence the probability of default.

For our study, we preferred to continue along the company-value approach suggested by the early work, mentioned above, numerically analyzed by two of ourselves, e.g., in Grüne and Semmler (2005), and made practical, through the widespread acceptance of Moody's KMV model. Crouhy, Galai, and Mark (2000) provide an excellent overview of the many approaches that have been found effective by practitioners. In particular, they analyze the implementation of the company-value approach in the commercial sphere. Moody's KMV (named for Kealhover, McQuown, and Vasicek, cofounders of the KMV Corporation) model calculates the Expected Default Frequency (EDF) based on the company's capital structure, the volatility of the assets returns and the current asset value. The model specifies the financial structure of the company in terms of assets, current debt, long-term debt, and preferred shares. Next, the default point (DPT), the asset value where the company defaults, is computed. It is assumed that this point is above the size of its short-term debt. 


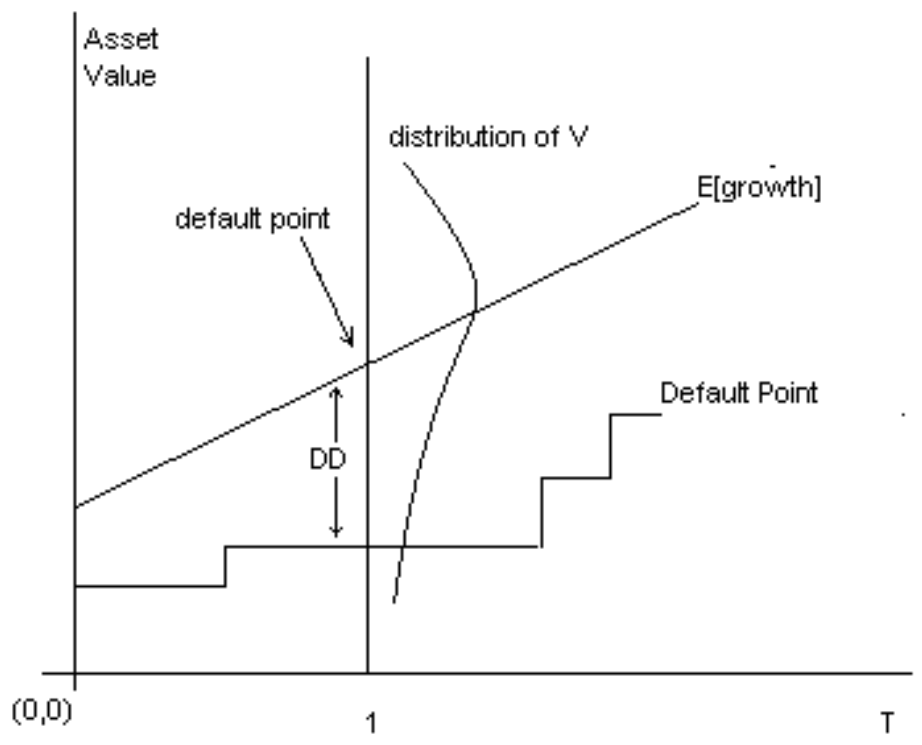

Figure 1: Distance-to-Default model

The distance-to-default, $D D$, is the number of standard deviations between the mean of the distribution of the assets value and the default point, where $E\left[V_{\text {growth }}\right]=$ Expected[asset value in 1 year], Default Point $=$ (short-term debt) $+\frac{1}{2}$ (long-term debt), and $\sigma=$ (volatility of asset returns). The last stage in this procedure is to construct a large list of companies, calculate their respective $D D$ s, and note the expected default frequency, $E D F$, as a function of $D D$. Thus an estimate of the $E D F$, based on valuation, capital structure, and the market as a whole is achieved. Thus, this model combines structural elements and historical data to estimate probability of default.

In our model, we will not use any actual data points, but will compute company value and the probability of default using a numerical approximation of the corresponding Hamilton-Jacobi-Bellman equation. The details of this are discussed, in general in section 5, and are found, in detail in Camilli and Falcone (1995), Camilli, et. al. (2006).

\section{Default Premia and Asset Pricing}

We are now in a position to discuss the background of the present project. Defining the value of the company's assets by $V$ and debt by $B$, we have $B=$ $F(V, t)$. On the maturity date $T$, one needs to have $V-\bar{B}>0$ with $\bar{B}$ being the promised payment, otherwise the company will default. Thus, the debt payment at maturity date $T$ is 


$$
F(V, T)=\min (V, \bar{B})
$$

In terms of a Brownian motion one can write a change of the value of debt as

$$
d B=\left(\alpha_{B} B-C_{B}\right) d t+\sigma_{B} B_{t} d z
$$

with $\alpha_{B}, \sigma_{B}$ and $C_{B}$ constants. Presuming $B=F(V, t)$ and a Brownian motion for the value of the underlying asset, $V$, by

$$
d V=\left(\alpha_{V} V-C_{V}\right) d t+\sigma_{V} V d z .
$$

A solution of the stochastic equation for the debt, $B$, depending on the stochastic process for $V$, can then be obtained by using Ito's lemma (see Merton, 1974).

Below in the context of a deterministic dynamic model, it will be shown that if there are no risk premia and the company issues debt at a risk free interest rate the debt value of the company is equal to its creditworthiness which will be proxied by the company's asset value. Thus we have as maximum debt capacity $B^{*}=V$. This will, however be different for an endogenous risk premium where the risk premia may depend on the extent to which the company is levered. Then, as shown below, we will have $B^{*}=F\left(V\left(B^{*}\right)\right)$, which is a more difficult problem to solve.

On the other hand, as noted above, recently, in economic theory, there has been much work on imperfect capital markets and companies' investments. Many dynamic models have been proposed where a company operates in an environment of imperfect capital markets and faces credit constraints. Here we, mainly, keep the focus on companies that may face an idiosyncratic default risk and default premia that may effect a company's optimal investment strategy. ${ }^{10}$

In the latter context, it is frequently posited that borrowers face a risk dependent-interest rate which is assumed to be comprised of a market interest rate, e.g., the risk-free interest rate, and an idiosyncratic component determined by the individual riskiness of the borrower. ${ }^{11}$ This gives rise to risk premia that companies have to pay contingent on their net worth. In this paper, the impact of both the credit constraint as well as endogenous risk premia on the company's optimal investment and asset value will be explored.

As to the justification of the default premium, we draw on the literature

\footnotetext{
${ }^{10}$ Investment models with credit market borrowing from imperfect capital markets can be found in Townsend (1979), Kiyotaki and Moore (1997), Bernanke, Gertler and Gilchrist (1999) and Miller and Stiglitz (1999). In these models, the impact of imperfect credit market borrowing and debt dynamics on economic activity is studied.

${ }^{11}$ Recently, the theory of asymmetric information and costly state verification has been employed, e.g., Bernanke, et al. (1999), where a risk premium is taken as endogenous by making the default risk dependent on net worth of the borrower.
} 
of asymmetric information and costly state verification. ${ }^{12}$ Such a premium ${ }^{13}$ drives a wedge between the expected return of the borrower and the risk-free interest rate. A simple assumption is that the premium is positively related to the default cost and inversely related to the borrowers net worth. Net worth is defined as the company's collateral value of the capital stock less the agent's outstanding obligations. ${ }^{14}$ We can then measure the inverse relationship between the risk premium (default premium) and net worth as follows:

$$
H(k(t), B(t))=\frac{\alpha_{1}}{\left(\alpha_{2}+\frac{N(t)}{k(t)}\right)^{\mu}} \theta B(t)
$$

with $H(k(t), B(t))$ the credit cost depending on net worth, $N(t)=k(t)-$ $B(t)$, with $k\left((t)\right.$ as capital assets and $B(t)$ as debt. The parameters are $\alpha_{1}, \alpha_{2}, \mu$ $>0$ and $\theta$ is the risk-free interest rate. In the analytical and numerical study of the model below we presume that the risk premium will be zero for $N(t)=k(t)$ and thus, in the limit, for $B(t)=0$, the borrowing rate is the risk-free rate. Borrowing at a risk-free rate will be considered here as a benchmark case. ${ }^{15}$

In Figure 2 eq. (1) is shown with the external finance premium which arises if $N(t)<k(t)$, yet note that different companies could face a different slope of such a default premium cost function. ${ }^{16}$

\footnotetext{
${ }^{12}$ This literature originates in the seminal work by Townsend (1979), in which lenders must pay a cost in order to observe the borrower's realized returns. This motivates the use of collateral in credit market models. Uncollateralized borrowing is assumed to pay a larger premium than collateralized borrowing or self-financing. The premium arises from the threat of bankruptcy, i.e., the costs of auditing, accounting, and legal, as well as the loss of assets arising from asset liquidation. In terms of observable variables, the premium the company has to pay is considered premium as arising from default risk.

${ }^{13}$ As Gomes, et. al. (2002) show for a large class of models, one can expect the external finance premium, indeed, to be equal to the premium necesssary to compensate lenders for the default risk. Gomes, et. al. (2002) measure the default risk by the spread of corporate bonds and T-bills. Another proxy is the relative size of external finance to capital, see Gomes, et. al. (2002).

${ }^{14}$ See Bernanke, Gertler and Gilchrist (1999)

${ }^{15}$ Another way to state the risk premium, and thus the risk structure of interest rates is as follows: assume there is debt with different maturity and that $R(\tau)-\theta$ is the risk premium with $R(\tau)$ the yield to maturity $\tau$ and $\theta$ the risk-free rate - see Merton (1974). Thus, $R(\tau)$ is, thus, implicitly defined by $e^{-R(\tau) \tau}=\frac{F(V, \tau)}{\bar{B}}$.

${ }^{16}$ Note also that for each firm, bonds with different maturity could have different risk premia which we will, however, disregard here.
} 


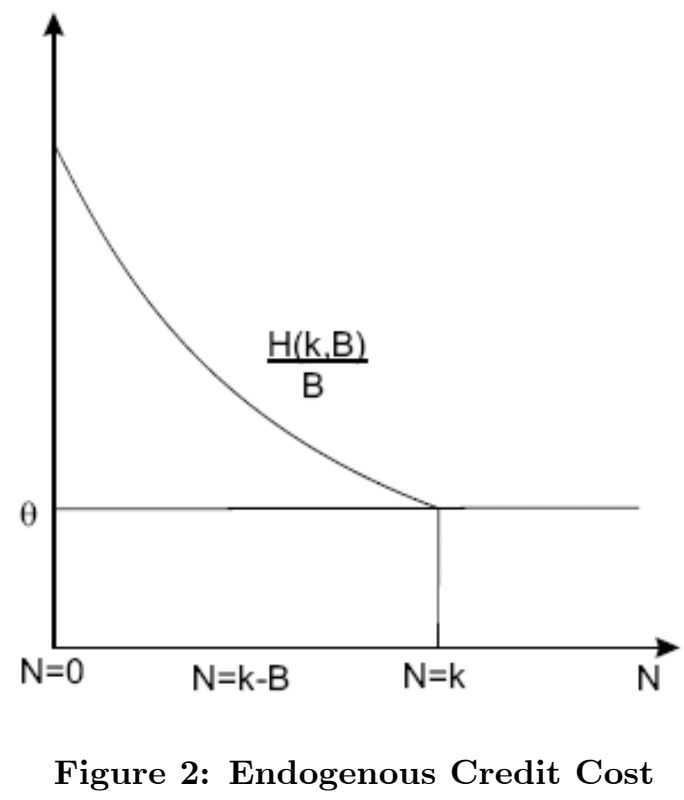

Herein, default premia are endogenized as shown above in figure 2. The default risk implied by endogenous credit costs, as well as upper constraints on borrowing, can affect the value of the company. In both cases, the net worth becomes an endogenous variable. We examine this using a modified HJB-equation and our numerical methods - as introduced in section 5. Moreover, we want to note that the risk-free rate does not need to be a constant; it could vary over time. ${ }^{17}$

\section{A Model with Endogenized Default Premia}

We will present our model in two steps. In the first, we have a deterministic version with a single productive asset, while the second step allows for a stochastic environment and diversification of the company's assets. In the latter case, depending upon which form of productive activity is being utilized, the productive assets are subject to random shocks. We thus imagine a company that is able to shift its resources across productive assets.

First, for the deterministic case, we specify the dynamic decision problem of a company that faces a default premia on its bonds as described in the previous section. In our model, as in Cochrane's $(1991,1996)$, asset pricing can be studied without reference to utility theory or a discount factor obtained from the growth rate of marginal utilities. ${ }^{18}$

\footnotetext{
${ }^{17}$ For details of such a model see Grüne, Semmler and Sieveking (2004).

${ }^{18}$ In Grüne, Semmler and Sieveking (2004), an analytical treatment is given of why and under what conditions the subsequent dynamic decision problem of a firm can be separated from the consumption problem.
} 
In step one, the company accumulates a productive asset through an optimal investment where debt can be continuously issued and retired. In each period the company does not have to pay attention to the maturity structure of its debt and it does not face one-period borrowing constraints. Yet, there can be intertemporal debt constraints that affect the present value of the activity of the company.

Using the risk premia formulated in eq. (1), we examine the following dynamic decision problem of a firm accumulating a productive asset. ${ }^{19}$

$$
\begin{gathered}
V(k)=\operatorname{Max}_{j} \int_{0}^{\infty} e^{-\theta t} f(k(t), j(t)) d t \\
\dot{k}(t)=j(t)-\delta k(t), \quad k(0)=k . \\
\dot{B}(t)=H(k(t), B(t))-f(k(t), j(t)), B(0)=B_{0}
\end{gathered}
$$

The company's net income

$$
f(k, j)=a k^{\alpha}-j-j^{\beta} k^{-\gamma}=a k^{\alpha}-j-\left(\frac{j}{k}\right)^{2} ; \text { when } \beta=\gamma=2
$$

arises from the productive assets, i.e., capital stock, through a production function, $a k^{\alpha}$; investment, $j$, is undertaken so as to maximize the present value of net income given the adjustment cost of capital $\varphi(k, j)=j^{\beta} k^{-\gamma}$. Note that $\delta>0, \alpha>0, \beta>1, \gamma>0$, are constants, eq. (3) represents the equation for the company's productive assets, and eq. (4), the evolution of debt for the company, represented by outstanding bonds. Since net income in (5) can be negative, the temporary budget constraint requires the further issuance of bonds (further borrowing from credit markets) and, if there is positive net income, debt can be retired. ${ }^{20}$

As shown above, we may assume that the risk premium in our credit cost function $H(k, B)$ is state-dependent, depending on the productive asset, $k$, and the level of debt $B$ with $H_{k}<0$ and $H_{B}>0$. Note, however, that if we assume that the default risk depends inversely on net worth, as in eq. (1), we recover a special case of our model where the credit cost is determined only by the

\footnotetext{
${ }^{19}$ Note that in order to recover the usual optimization problem for linear credit cost, we state our optimization problem in such a way so as to include the limiting case where there is a linear credit cost. However, our numerical procedure can solve the more difficult problem where there are state dependent default premia.

20 The productive activity of the company can also be interpreted as written in efficiency labor, therefore $\delta$ can represent the sum of the capital depreciation rate, and rate of exogenous technical change. Note that in (3) a consumption stream could be included. In the study by Grüne, Semmler and Sieveking (2004) such a consumption stream is treated.
} 
risk-free interest rate. We then have a linear model with constant credit cost, $\theta$, and a state equation for the evolution of debt:

$$
\dot{B}(t)=\theta B(t)-f(k, B), \quad B(0)=B_{0}
$$

We consider this our benchmark case and we only have to consider the transversality condition $\lim _{t \rightarrow \infty} e^{-\theta t} B(t)=0$, as the non-explosiveness condition for debt, to close the model and eq. (2) would give us the company's asset value.

Unfortunately, Pontryagin's maximum principle is not suitable for solving this problem with endogenous default premium and endogenous net worth. Thus, we use numerical methods to solve for the present value and investment strategy of a levered company.

Ignoring time subscripts, for constant interest rates (no time-varying risk premia) the HJB equation for eqs. (2)-(4), where $B^{*}=V$, may be written

$$
\theta V=\max _{j}\left[f(k, j)+\frac{d V(k)}{d k}(j-\delta k)\right]
$$

In the general case of eq. (2)-(4), with company-specific default risk and the default premium as stated in eq. (1) and shown in Figure 1, we have the following modified HJB-equation instead:

$$
H\left(k, B^{*}(k)\right)=\max _{j}\left[f(k, j)+\frac{d B^{*}(k)}{d k}(j-\delta k)\right]
$$

Note that in the limiting case, where there is no borrowing, $N=k$, and we have a constant discount rate $\theta$, we obtain the HJB-equation (7). The HJBequation (8) can be written as

$$
B^{*}(k)=\max _{j} H^{-1}\left[f(k, j)+\frac{d B^{*}(k)}{d k}(j-\delta k)\right]
$$

which is a standard dynamic form of a HJB-equation. Next, for example, let us specify $H(k, B)=B^{\kappa} \theta$ where, with $\kappa>1$ the interest payment is solely convex in $B$. We then get

$$
B^{*}(k)=\max _{j}\left[f(k, j)+\frac{d B^{*}}{d k}(j-\delta k)\right]^{\frac{1}{\kappa}} \theta^{-\frac{1}{\kappa}}
$$

As can be shown for eq (10), with $\kappa>1$, the same equilibrium emerges as for (7). The algorithm used to study the more general problem of eq. (9) is described in section 5 .

Note that in the case of $\kappa>1, B^{*}(k)$, eq. (8), will be smaller than $V(k)$, eq. (7). There is an additional default cost to be paid which is not present in eq. (6), the integral of which will drive a wedge between the present value $V(k)$ and $B^{*}(k)$. Thus, $B^{*}(k)<V(k)$ will hold. 
Employing our general form for default premium ${ }^{21} H(k, B) \geq \theta B$, the debt capacity, $B^{*}(k)$, relates to the asset value of the company for $B(t) \leq B^{*}(k(t))$ as follows.

$$
V(k)=B^{*}(k)+V_{H}\left(k, B^{*}(k)\right) .
$$

For the case $H(k, B)=\theta B$ we have $V(k)=B^{*}(k)$; for the case of an endogenous default premium $H(k, B)$, where we have $H\left(k, B^{*}(k)\right)$, the debt capacity will be less than $V(k)$. Yet, whenever $B<B^{*}$ the value of the company's assets can be represented by stocks and bonds, thus permitting a consumption stream for the owner of the stocks. Yet, as we have pointed out above, the company's asset value may also be affected by the default premium.

The second step in our model expands upon the above to include a stochastic environment and thus move closer to real-world situations. Let us assume a simple case where the company's total assets may be diversified into two different types of productive assets which may, in turn, be subject to correlated shocks. Thus, as concerns total assets and potential earnings, the weight, $w$, devoted to one line of productive assets will be valued differently than that, $1-w$, devoted to the other. The following equation states that the total cash income to the company is generated by the respective portions in each productive asset minus the adjustment costs and reinvestment.

$f(k, j)=a_{1}(w k)^{\alpha_{1}}-(w j)^{\beta_{1}}(w k)^{-\gamma_{1}}+a_{2}((1-w) k)^{\alpha_{2}}-((1-w) j)^{\beta_{2}}((1-w) k)^{-\gamma_{2}}-j$

For example, we might imagine that the company allocates its productive assets at the beginning of each year and a decision is made as to which major productive activities should be undertaken. We presume that the company is able to shift its resources around in a fairly fluid manner, thus, it may change the percentage of its resources, $w$, that are devoted to one activity or the other, 1-w, at will. Each productive activity is subject to random shocks. Prior knowledge of the markets yields information about the expected correlations between the different productive activities. Thus, a choice as to what to produce is made at the beginning of the year with respect to, among other things, correlation.

The company directors have two decisions to make:

1) What percentage of the company's assets need to be channeled into product-A production, $w$, and what percentage into product-B, 1-w?

2) What amount of revenues should be reinvested, $j$, in the company as a whole?

Both decisions are undertaken in such a way as to maximize the present value of the company as seen from a discounted future income perspective. We assume that the amount of revenue thus generated will be dependant upon

\footnotetext{
${ }^{21}$ For more details of the subsequent derivations, see Grüne, Semmler and Sieveking (2004).
} 
the relative weight of the overall resources that are devoted to the respective productive assets and to parameters specifically related to them.

Thus, there are two control variables, $w$ and $j$. The total assets, $k$, will be influenced by the natural depreciation rate and by additional investment. Following the logic of our model, we further presume that equity is increased by retiring debt as quickly as possible. Thus, while positive cash flow may be used to pay off bonds or to reinvest in the company, negative cash flow will require the issuance of new bonds. Because of the complex way in which the random shocks effect the value of the company's assets, depending also on whether it has been shunted into one or the other line of production, and because of the nonlinear way in which revenues are generated, the optimal decision path is not obvious.

We are interested in discovering how differences in the correlation between the shock processes effect the probability of default. Thus, our objective equation remains ${ }^{22}$

$$
V(k)=\operatorname{Max}_{j} \int_{0}^{\infty} e^{-\theta t} f(k(t), j(t)) d t
$$

Small changes in capital are now the sum of the differences between mean reinvestment of cash inflows and depreciation (for each line of production) plus stochastic shocks, proportional to weight, to the productive assets invested in each line of production. So, the evolution of total productive assets can be described by

$$
\begin{aligned}
& d k(t)=\left(j(t)-k(t)\left(\delta_{1} w+\delta_{2}(1-w)\right) d t+k_{t}\left(w \sigma_{1} d X_{1}(t)+(1-w) \sigma_{Y} d Y_{\rho}(t)\right)\right. \\
& \text { and }^{23}
\end{aligned}
$$

$$
d B(t)=H(k(t), B(t))-f(k(t), j(t)) d t
$$

where $Y_{p}$ is a process correlated, with coefficient $\rho$, with the random process $X_{1}$ We can imagine that the company's total assets have been invested in diversified capital assets that are subject to shocks in different ways. ${ }^{24}$ It is

\footnotetext{
22 Some readers may remark at the "missing" Expected Value notation. These are, indeed, missing in eqs. (2) and (12). However, formally, this is no problem as we only use the optimization criteria, (2) and (12), for the deterministic and linear versions of the model; as described in Section 5: in the nonlinear deterministic and the stochastic version we do not maximize $\mathrm{V}$ from eqs. (2) and (12), but rather we maximize $\mathrm{B}^{*}$ or the default probability, respectively.

${ }^{23}$ We note that this equation combines the evolution of two productive assets subject to correlated random shocks. Thus, there are two random, but correlated, processes that are both contributary: $\left\{\begin{array}{c}d k_{w}(t)=k(t) w_{t}\left(\delta_{w} d t+\sigma_{1} d X_{1}\right) \\ d k_{w-1}(t)=k(t)\left(1-w_{t}\right)\left(\delta_{w-1} d t+\sigma_{Y} d Y_{\rho}\right)\end{array}\right\}$

${ }^{24}$ We might assume that the shock to the diversified capital assets comes through shocks to the market performance of those assets and are translated into shocks to the accumulated capital stock. Tobin's (1969) $q$ theory of investment could help us to explain why external shocks are transmitted to the captial assets.
} 
easy to generate two random variables with a specified correlation using the relation:

$$
Y_{\rho}=\rho X_{1}+\sqrt{1-\rho^{2}} X_{2}
$$

where $X_{1}$ and $X_{2}$ are uncorrelated random numbers and $\rho$ is the desired correlation. Thus $X_{1}$ and $Y_{\rho}$ are random variable with correlation coefficient $\rho$.

Thus, in this second step, we are able to study the effect of different types of correlation between the disturbances, those to the fractions of the company's assets devoted to one or the other productive activity, on the probability of default. As will be shown, this version reduces to base cases for appropriate choices for $\rho$.

\section{$5 \quad$ Numerical Solution Methods}

In this section, we present the numerical procedures with which we have numerically solved for the maximal debt capacity and default probabilities. We introduce numerical methods for the deterministic as well for the stochastic cases.

\subsection{Computation with Risk-Free Rate}

The following dynamic programming (DP) algorithm ${ }^{25}$ can be applied to solve discounted infinite horizon optimal control problems of the type found in (2)(4). This is applicable because there is no default premium and no restrictions on the dynamics are present. In our model, this applies when the model is linear, i.e., $H(k, B)=\theta B$ as in (9) and if, in addition, the constraint on $B$ is given by $\inf _{j} \sup _{t \geq 0} B(t)<\infty$, since, in this case, it follows that $B^{*}(k)$ is easily obtained from $V(\bar{k})$ in $(2)$, namely from

$$
V(k)=\operatorname{Max}_{j} \int_{0}^{\infty} e^{-\theta t} f(k(t), j(t)) d t
$$

The algorithm was originally developed over twenty years ago by I. Capuzzo Dolcetta (1983), and has been subsequently refined, Falcone (1987) and Grüne (1997). For details and for a mathematically rigorous convergence analysis we refer to the work by Bardi and Capuzzo Dolcetta (1997) and to Grüne, Metscher and Ohlberger (1999).

\footnotetext{
${ }^{25}$ For a further discussion of the dynamic programming algorithm and more detailed applications in economics, see Grüne and Semmler (2004, 2007).
} 
In the first step, the continuous time optimal control problem is replaced by a first order discrete time approximation given by

$$
V_{h}(k)=M_{j} \underset{j}{ } J_{h}(k, j), \quad J_{h}(k, j)=h \sum_{i=0}^{\infty}(1-\theta h)^{i} f\left(k_{h}(i), j_{i}\right)
$$

where $k_{h}$ is defined by the discrete dynamics

$$
k_{h}(0)=k, \quad k_{h}(i+1)=k_{h}(i)+h\left(j_{i}-\sigma k_{h}(i)\right)
$$

and $h>0$ is the discretization time step. Note that $j=\left(j_{i}\right)_{i \in \mathbb{N}_{0}}$ here denotes a discrete control sequence.

The optimal value function is the unique solution of the discrete HamiltonJacobi-Bellman equation

$$
V_{h}(k)=\operatorname{Max}_{j}\left\{h f\left(k, j_{0}\right)+(1-\theta h) V_{h}\left(k_{h}(1)\right)\right\},
$$

where $k_{h}(1)$ denotes the discrete solution corresponding to the control $j$ and initial value $k$ after one time step $h$. Abbreviating

$$
T_{h}\left(V_{h}\right)(k)=\operatorname{Max}_{j}\left\{h f\left(k, j_{0}\right)+(1-\theta h) V_{h}\left(k_{h}(1)\right)\right\}
$$

The second step of the algorithm now approximates the solution on a grid, $\Gamma$, covering a compact subset of the state space, i.e., a compact interval $[0, K]$ in our setup. Denoting the nodes of $\Gamma$ by $k^{i}, i=1, \ldots, P$, we are now looking for an approximation $V_{h}^{\Gamma}$ satisfying

$$
V_{h}^{\Gamma}\left(k^{i}\right)=T_{h}\left(V_{h}^{\Gamma}\right)\left(k^{i}\right)
$$

for each node $k^{i}$ of the grid, where the value of $V_{h}^{\Gamma}$ for points $k$ which are not grid points (these are needed for the evaluation of $T_{h}$ ) is determined by linear interpolation. We refer to the work cited above for the description of iterative methods. Note that an approximately optimal control law (in feedback form for the discrete dynamics) can be obtained from this approximation by taking the value $j^{*}(k)=j$ for $j$ realizing the maximum in (18), where $V_{h}$ is replaced by $V_{h}^{\Gamma}$. This procedure yields the numerical computation of approximately optimal trajectories.

In order to distribute the nodes of the grid efficiently, we make use of an $a$ posteriori error estimation. For each cell $C_{l}$ of the grid $\Gamma$ we compute

$$
\eta_{l}:=\underset{k \in C_{l}}{\operatorname{Max}}\left|T_{h}\left(V_{h}^{\Gamma}\right)(k)-V_{h}^{\Gamma}(k)\right|
$$

(In other words, we approximate this value by evaluating the right hand side in a number of test points). It can be shown that the error estimators $\eta_{l}$ give upper and lower bounds for the real error (i.e., the difference between $V_{h}$ and $\left.V_{h}^{\Gamma}\right)$ and hence serve as an indicator for a possible local refinement of the grid $\Gamma$. 
It should be noted that this adaptive refinement of the grid is very effective ${ }^{26}$ for detecting thresholds, because the optimal value function typically fails to be differentiable in these points, resulting in large local errors and consequently in a fine grid.

\subsection{Computation with Default Premium}

In the more general model, i.e., where there is a default premium defined by $H(k, B)$ in (1) and/or restrictions of the type $B / k \leq c$, the above DP-algorithm, regrettably, is not applicable. It is true that, in certain cases, a HJB-equation for a discrete time version of the problem is available. However, it is not clear whether the full discretization procedure described above leads to a valid and convergent approximation of the asset price and the present value borrowing constraint.

Hence, we employ a different approach for the solution of this problem. This is a set oriented method for the computation of domains of attraction. ${ }^{27}$ The method relies on the following observation: For a given compact interval 28 $[0, K]$ for the capital stock $k$ one sees that there exists a constant $c^{*}>0$ such that $B^{*}(k) \leq c^{*}$ for all $k \in[0, K]$. Here, we denote $B^{*}(k)$ as the borrowing constraint of the firm. Hence, for $k \in[0, K]$ the condition $\sup _{t \geq 0} B(t)<\infty$ can be replaced by

$$
\sup _{t \geq 0} B(t)<c^{*} .
$$

Hence both this constraint and the constraint $B(t) \leq c k(t)$ can be expressed as

$$
B(t) \leq d(k(t)) \text { for all } t \geq 0
$$

for some suitable function $d$. In other words, the set of all initial values $\left(k_{0}, B_{0}\right)$ for which this constraint is violated is given by

$$
D=\left\{\begin{array}{l|l}
\left(k_{0}, B_{0}\right) & \begin{array}{l}
\text { there exists } T>0 \text { such that } B(t(j)) \geq d(k(t(j))) \\
\text { for all } j \text { and some } t(j) \in[0, T]
\end{array}
\end{array}\right\}
$$

and the curve $B^{*}(k)$ is exactly the lower boundary of $D$. For details of how the domains of attraction are computed, see Grüne and Semmler (2005). Equipped with the above two algorithms the firm's asset value and thus the maximum debt capacity $B^{*}$ can be computed.

\footnotetext{
${ }^{26}$ Actually, for the one-dimensional problem at hand it is possible to compute rather accurate approximations $v_{h}^{\Gamma}$ also with equidistributed grid points. In higher dimensions the computational advantage of adaptive gridding is much more obvious, see, e.g., the examples in Grüne (1997) or Grüne et al. (1999).

${ }^{27}$ For a more detailed description of the algorithm, see Grüne and Semmler (2005)

${ }^{28}$ In any numerical method we must restrict ourselves to a compact computational domain, hence this restriction is natural in this context.
} 


\subsection{Computation of Default Probabilities}

In order to explain the numerical algorithm for the computation of the probability of default in the stochastic case, let us write the model in a general form, using the brief notation

$$
\begin{cases}d X(t) & =b(X(t), u(t)) d t+\sigma(X(t), u(t)) d W(t) \\ X(0) & =x_{0}\end{cases}
$$

with $X(t)=(k(t), B(t)) \in \mathbb{R}^{2}$. Then, defining $K=\left\{(k, B) \in \mathbb{R}^{2} \mid B \leq 0\right\}$ determining the minimal default probability amounts to computing the function

$$
p\left(x_{0}\right):=1-\inf _{u} \mathbb{P}\left\{X_{t}\left(x_{0}, u\right) \rightarrow K \text { as } t \rightarrow \infty\right\} .
$$

In order to compute this function $p$, consider the Hamilton-Jacobi-Bellman equation, called the stochastic Zubov equation,

$$
\sup _{u \in U}\{-\mathcal{L}(x, u) v(x)-\delta g(x)(1-v(x))\}=0
$$

for $x=(k, B) \in \mathbb{R}^{2}$. Here $g$ is a continuous function with $g(x)=0$ for $x \in K$ and $g(x)>0$ for $x \neq K$ (we use $g(x)=B^{2}$ for $B>0$ in our computations), $\delta>0$ is a real valued parameter and

$$
\mathcal{L}(x, u) \cdot:=\frac{1}{2} \sum_{i, j=1}^{2} a_{i j}(x, u) \frac{\partial^{2} \cdot}{\partial x_{i} \partial x_{j}}+\sum_{i=1}^{2} b_{i}(x, a) \frac{\partial \cdot}{\partial x_{i}}
$$

denotes the generator of the Markov process associated to (19) where $a_{i, j}$ are the entries of the matrix $\sigma \sigma^{T}$.

It was proved in Camilli, Cesaroni, and Grüne (2002) that (20) possesses a unique viscosity solution $v_{\delta}$ depending on the parameter $\delta>0$ which satisfies

$$
v_{\delta}(x) \rightarrow p(x) \quad \text { as } \quad \delta \rightarrow 0
$$

In order to approximate $p(x)$ we compute $v_{\delta}(x)$ for $\delta=10^{-4}$ and perform a regularization and semi-discretization of (20) following Camilli, Grüne, and Wirth (2000) and Camilli and Falcone (1995) ${ }^{29}$.

For regularization parameter $\varepsilon>0$ and time step $h>0$ (in our computations we used $\varepsilon=10^{-4}$ and $\left.h=1 / 20\right)$ this yields the equation

$$
v(x)=\min _{u \in U} \mathbb{E}\left\{h \delta g(x)+\left(1-h \delta g_{\varepsilon}(x)\right) v\left(\varphi_{h}(x, u)\right)\right\} .
$$

with

$$
g_{\varepsilon}(x)=\max \{\varepsilon, g(x)\} \quad \text { and } \quad \varphi_{h}(x, u)=x+h b(x, u)+z \sigma(x, u),
$$

${ }^{29}$ See Grüne (2005) for details. 
where $z$ is a two-point distributed random variable which assumes the values $\pm \sqrt{h}$ with probability $1 / 2$ ( $\varphi$ is the discretization of (19) using the simplified weak Euler scheme, cf. Kloeden and Platen (1999)).

Finally, using the techniques from Grüne $(2005)^{30}$, we can use a dynamic programming algorithm in order to solve (21) on a grid with adaptive state space refinements.

${ }^{30}$ Also see Grüne and Semmler (2004). 


\section{Results of the Numerical Study}

Before discussing the results of the numerical analysis, we note that the deterministic case may actually be considered a special case of our more general model (second step), i.e., one in which $w$ is fixed at 0.5 and $\rho=-1$. In this case, the random shocks to different productive assets exactly balance each other, on average, thus returning us to the deterministic case. Additionally, for $\rho=1$, we get the equivalent special case of a single random shock process. For all cases we specify the company's technology parameters to be the same namely $\sigma=0.15, A=0.29, \alpha=0.7, \beta=2, \gamma=0.3$ and $\theta=0.1$, so that results do not differ because of different technology parameters. ${ }^{31}$ The results that we obtain, therefore, are solely attributable to the issuance of the company's risky debt. The remaining parameters are specified below. ${ }^{32}$

All examples were computed for different $k^{\prime} s$ in the compact interval $[0,2]$, using the set-oriented method described in section 5 , with control range $j \in$ $[0,0.25]{ }^{33}$ The dynamic programming algorithm uses the numerical time step $h=0.05$ and an initial grid with 39 nodes. The final adapted grid consisted of 130 nodes. The range of control values was discretized using 101 equidistributed values. ${ }^{34}$ In order to generate the discrete time model $\Psi$ we used an extrapolation method. For this, the range of control values was discretized using 51 equidistributed values. The domain covered by the grid was chosen to be $[0,2] \times[0,3]$ where the upper value $\bar{B}=3$ coincides with the value $c^{*}=3$, used in order to implement the restriction $\sup _{t \geq 0} B(t)<\infty$. The initial grid was chosen with 1024 cells, while the final adapted grids consisted of about 100000 to 500000 cells, depending on the example. For this algorithm, the figures below always show the set $E_{\Gamma}$ which approximates the present value curve $V(k)$. Recall that the width of this set gives an estimate for the spatial discretization error.

\subsection{Deterministic Version}

First, we consider our deterministic formulation. In our benchmark case, debt is issued, but with no default premium. Thus, the credit cost is given by $H(k, B)=\theta B$. In this case, we can use the DP algorithm in order to solve the discounted infinite horizon problem (2)-(4). Figure 3 shows the corresponding optimal value function representing the present value curve, $V(k)$. The present value curve represents the asset value of the company for initial conditions $k(0)$.

\footnotetext{
${ }^{31}$ For details regarding this parameter choice, see Grüne and Semmler (2005).

${ }^{32}$ Note that we, of course, could choose another source of heterogeneity of company's capital assets, namely by assuming different technology parameters for the company's productive assets. This might be another line of research which we will not pursue here.

${ }^{33}$ In all our experiments larger control ranges did not yield different results.

${ }^{34}$ Grüne and Semmler (2005) describes the set-oriented method in more detail.
} 


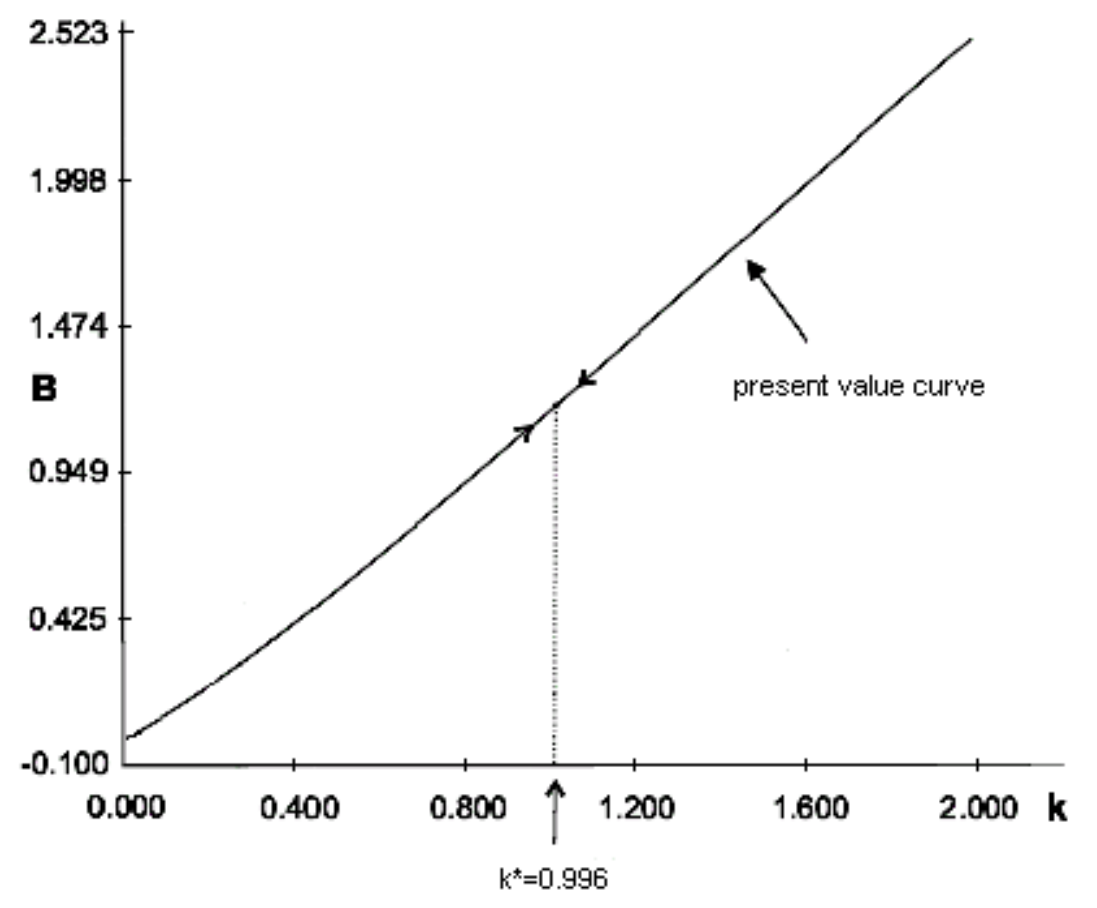

Figure 3: Present Value of Company's Capital Assets

We may consider that the debt control problem is solved whenever debt is bounded by the firm's asset value, so that we have $V-B \geq 0$. The optimal investment strategy is not constrained and thus the asset value which represents the maximum debt capacity $B^{*}$, is obtained by a solution for an unconstrained optimal investment strategy, represented by the present value curve in Figure 3. For initial values of the capital assets above or below $k^{*}$, the optimal trajectories tend to the domain of attraction $k^{*}=0.996$. For all of those different initial conditions, the debt dynamics remain bounded as long $V-B \geq 0$, thus allowing the company's equity holders to exercise the option of retiring the debt. Any initial debt above the present value curve will render the company unable to pay its obligations

Where a default premium is to be paid, the more general case, we used the following function to represent risk premia:

$$
H(k(t), B(t)))=\frac{\alpha_{1}}{\left(\alpha_{2}+\frac{N(t)}{k(t)}\right)^{\mu}} \theta B(t)
$$

For the model described in (2)-(4), with a risk premium included in the company's borrowing cost, it is not possible to transform the model into a standard infinite horizon optimal control problem. This follows because debt is now an additional constraint on the optimization problem. Hence, we will use the set-oriented method (as described in sect. 5) for the computation of domains 
of attractions and undertake experiments for different shapes of the credit cost function representing different alternative functions for the risk premium. An important class of functions for risk premia is defined by the steepness of the slope defined by the parameter $\alpha_{2}$.

In the above risk premium function we specify $\mu=2$. Taking into account that we want $\theta$ to be the risk-free interest rate, we obtain the condition $\alpha_{1} /\left(\alpha_{2}+\right.$ $1)^{2}=1$ and thus $\alpha_{1}=\left(\alpha_{2}+1\right)^{2}$. Note that for $\alpha_{2} \rightarrow \infty$ and $0 \leq B \leq k$ one obtains $H(k, B)=\theta B$, i.e., the model depicted in figure 3 .

Figure 4 shows the respective present value curves $V(k)$ for $\alpha_{2}=100,10,1$ , $\sqrt{2}-1$ (from top to bottom) and the corresponding $\alpha_{1}=\left(\alpha_{2}+1\right)^{2}$.

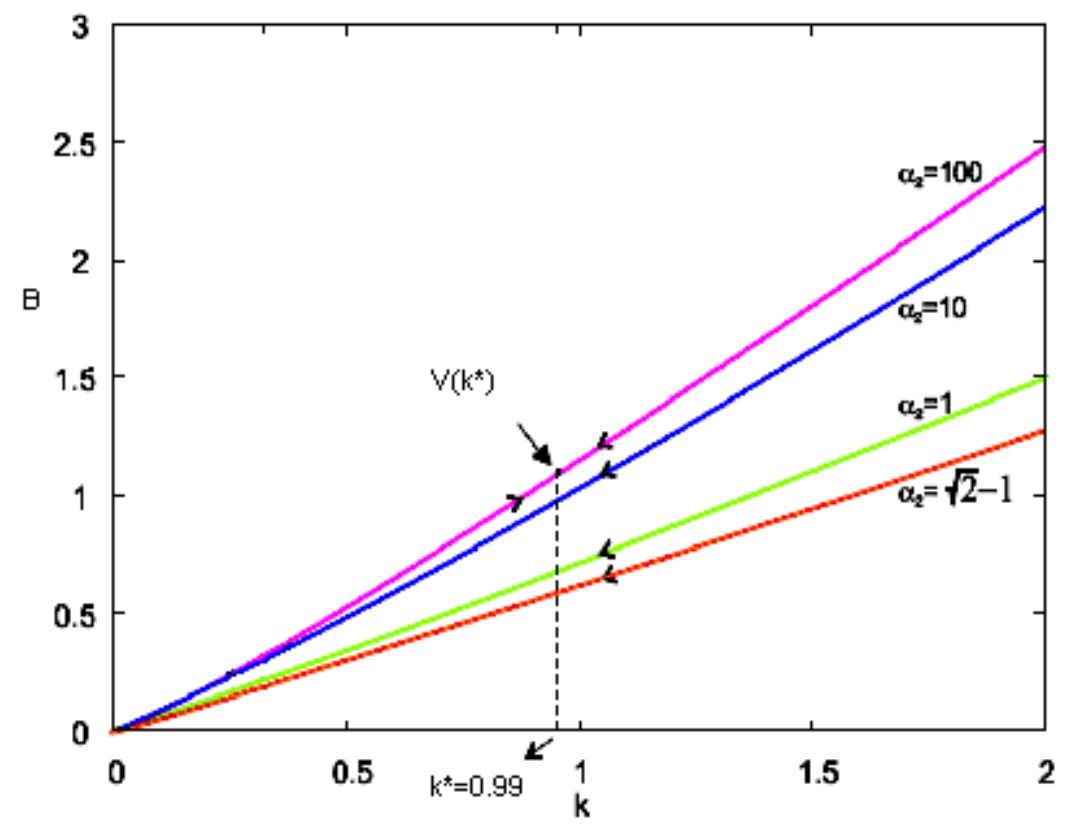

Figure 4: Present value curve $V(k)$ for different $\alpha_{2}$

For $\alpha_{2}=100$ firm's asset value and the trajectories on the curve $V(k)$ show almost the same behavior as those in the previous section: There exists a value of $\alpha_{2}$ where the company's asset value converges towards 0 . The trajectory for $\alpha_{2}=10$, as well as the other trajectories, show how the value function, and thus the company's asset value, is smaller the larger the default risk resulting from low net worth. Thus, a state dependent default risk has the same effect on firm value as a higher discount rate in standard $q$-theory of investment. The debt capacity curve, $B^{*}$, moves down due to higher credit cost (higher default risk) and if the debt rises such that the debt constraint curve, $B^{*}(k)$, is reached, the net assets of the company shrink to zero; thus, $V-B=0$ and no equity value claim on the net income stream of the firm can be supported. 


\section{The Stochastic Case}

Next, we consider a stochastic version of our model:

$$
\begin{aligned}
\dot{k}(t) & =(j(t)-\delta k(t)) d t+\sigma k(t) d X(t) \\
\dot{B}(t) & =(H(k(t), B(t)))-f(k(t), j(t)) d t
\end{aligned}
$$

with $H(k(t), B(t))$ as defined as eq. (1), $\sigma$ the standard deviation and $d X(t)$ the Brownian motion. With $\sigma=0$ we recover the deterministic dynamics (3)-(4). The problem of asset and debt valuation as well as the controllability problem then becomes to steer the system to the set $B \leq 0$, i.e. to debt bounded in the long run. Again, we use our standard parameters from section $5, \alpha_{2}=100$, $\alpha_{1}=\left(\alpha_{2}+1\right)^{2}$ and $\mu=2$. Details of the numerical procedure are given in Section 5. With this graph, we have taken the $k \times B$ plane of the previous two illustrations and added $\operatorname{Pr}($ Default $), p$, as a third.
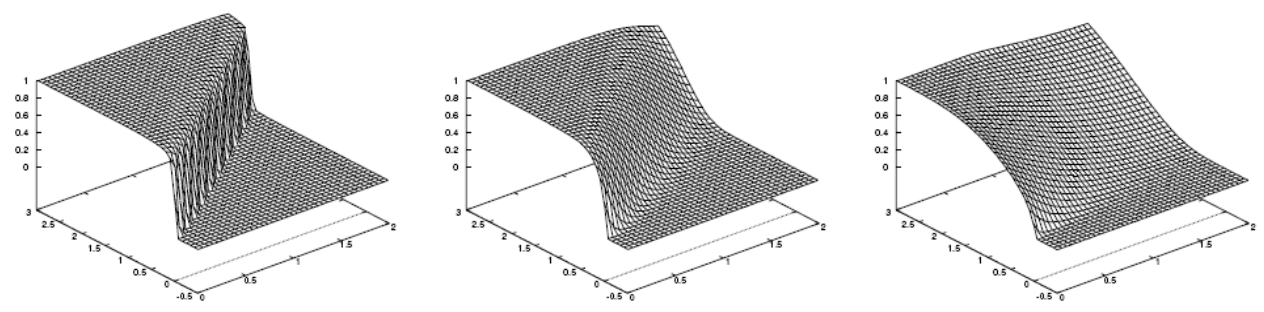

Figure 5: Numerically determined probabilities for $\sigma=0, \frac{1}{10}, \frac{1}{2}$

Figure 5 shows the numerical results for $\sigma=0, \frac{1}{10}$ and $\frac{1}{2}$ The case $\sigma=0$ corresponds to our deterministic version, where the probability of no controllability and thus bankruptcy is just 0 or 1 , and the line in the $[3,-0.5] \times[0,2]$ plane is just our maximum debt capacity $B^{*}=V$. As can be observed from the stochastic cases $\sigma=\frac{1}{10}$ and $\sigma=\frac{1}{2}$ the line of critical debt $B^{*}=V$ moves down; thus, in a stochastic environment, the likelihood of bankruptcy is rising due to unexpected income shocks and the credit worthiness is shrinking.

However we will see interesting differences in the stochastic case where we have diversifiable capital assets. We recall the equations of evolution for both debt and capital:

$$
\begin{gathered}
d k(t)=\left(j(t)-k(t)\left(\delta_{1} w+\delta_{2}(1-w)\right) d t+\sigma_{1} d X_{1}(t)+\sigma_{2} d Y_{\rho}(t)\right. \\
\dot{B}(t)=\theta B-f(k(t), j(t)-c(t)), B(0)=B_{0}
\end{gathered}
$$

We first examine the case where $w=\frac{1}{2}, \rho=-1$ 


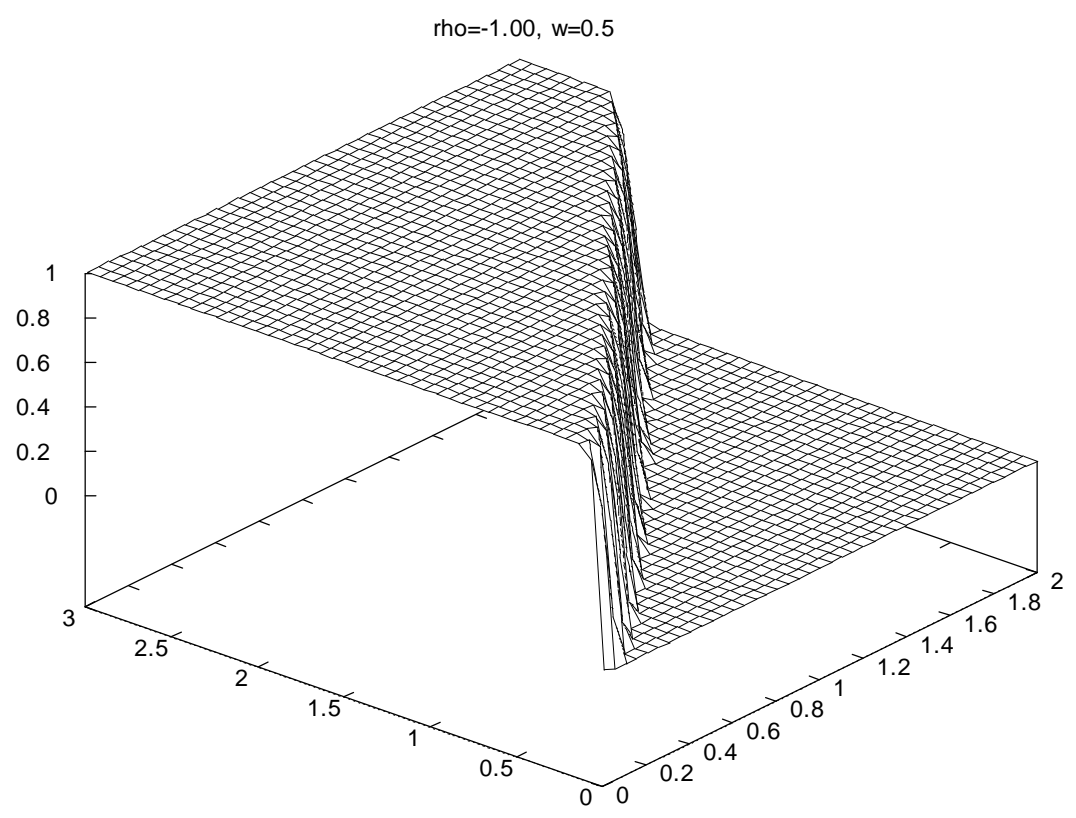

Figure 6: 50:50 Diversification, $\rho=-1$

Here, as anticipated, we recover the first case shown in figure 6. In this case, the two stochastic processes cancel each other out and we are left with a deterministic situation. In the next case, we consider $\rho=1$. 


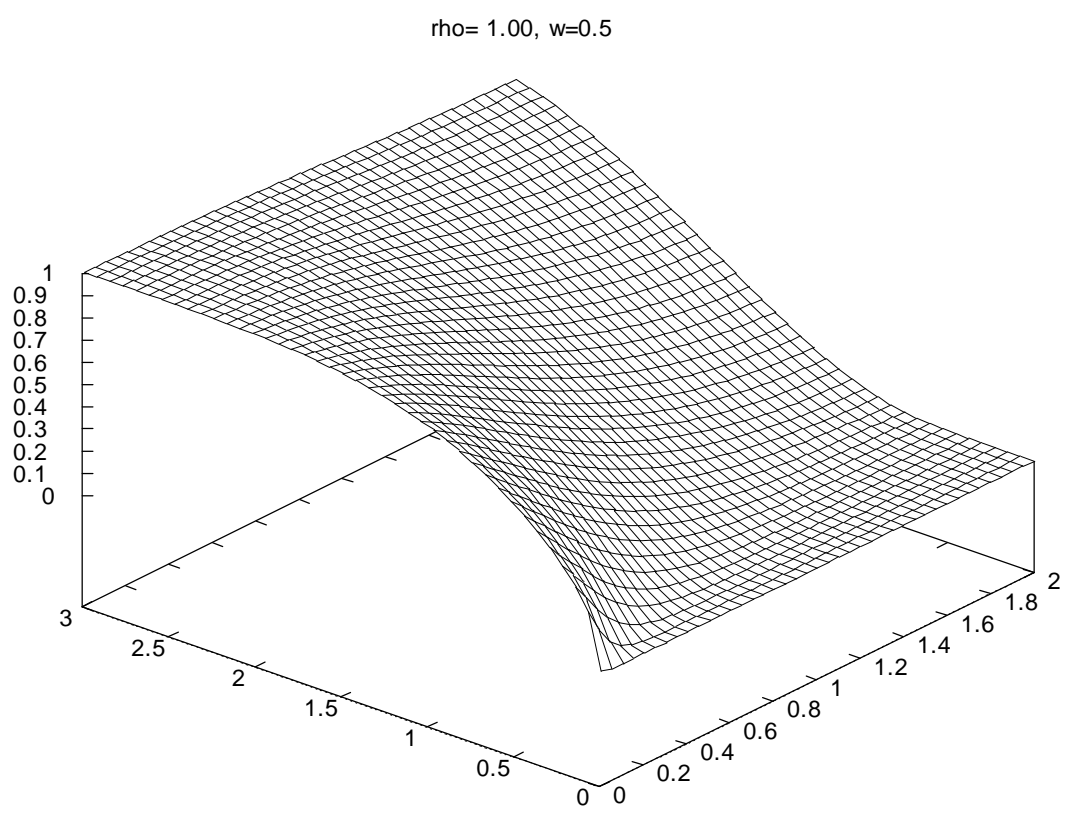

Figure 7: 50:50 Diversification, $\rho=1$

Now we recover a case similar to the last case of figure 5. Since the two processes are exactly correlated, it is the same as having a single process.

In order to understand the next few graphs, we consider what happens if we let $w$ be a control variable. Considering the first diagram (figure 7 ) for $B<B^{*}$, the deterministic system yields default probability $p=0$ for $w=\frac{1}{2}$. Thus, the company managers will choose $w=\frac{1}{2}$ here. However, for $B>B^{*}$, the choice $w=\frac{1}{2}$ yields $p=1$, thus deviating from $w=\frac{1}{2}$ can only decrease $p$; in other words, choosing $w \neq \frac{1}{2}$ introduces stochasticity to the system which increases the chances of surviving when $B>B^{*}$. We now consider a sequence with different correlation, $\rho$, between the productive assets and $w$ as a control variable. 


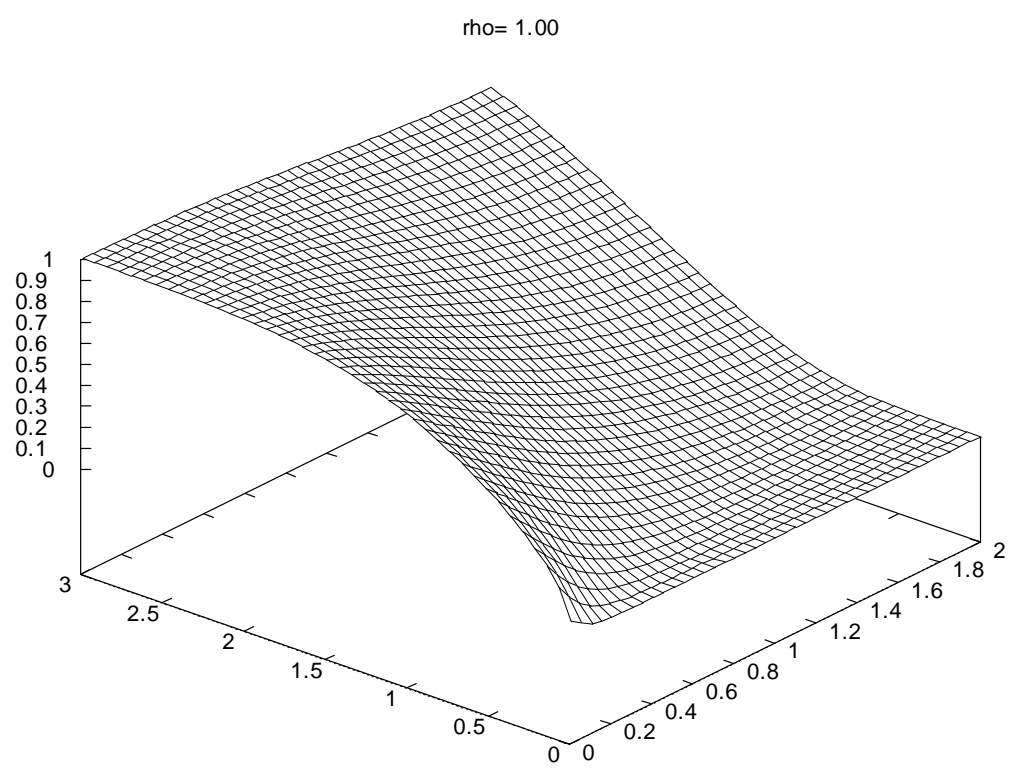

Figure 8: Full Freedom to Diversify, $\rho=1$

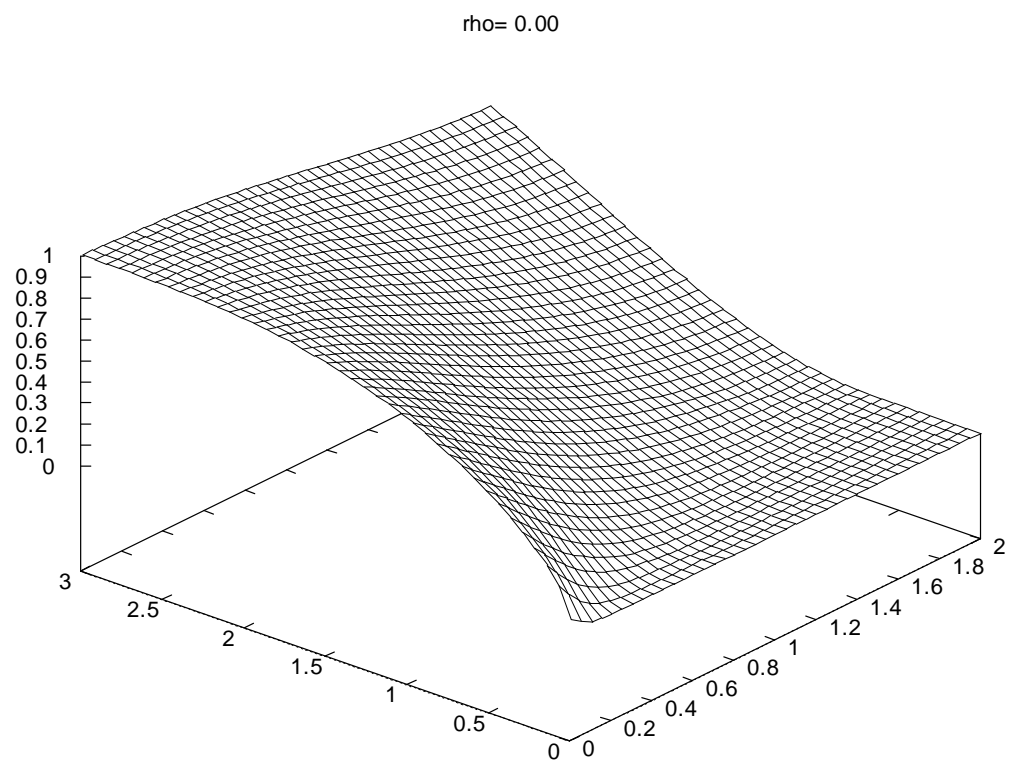

Figure 9: Full Freedom to Diversify, $\rho=0$ 


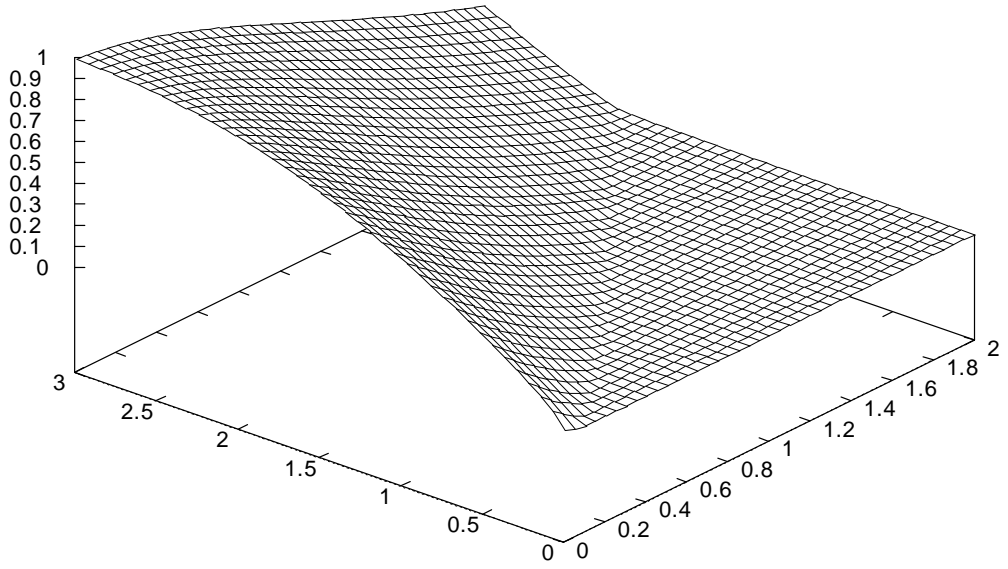

Figure 10: Full Freedom to Diversify, $\rho=-1$

Although the changes from figure 8 to figure 9 are subtle, we may note a slight "flattening" of the default-risk surface. More distinctly, in figure 10, we see that allowing the company's managers the freedom to shift the weights of the productive assets enables them to not only maintain a large region of safety when $B<B^{*}$, but to also have only a gradual escalation of risk when $B>B^{*}$. Further, even at the extreme range of $(B=3, k=2)$, there is still a positive probability of solvency! This is because although the company may be close to insolvency in the deterministic case, the probability of a positive shock implies a possibility for survival.

\section{Conclusions}

In this paper we have examined a company's default risk in the context of a dynamic decision problem where companies can borrow from the credit market for investment, where there is a risk premium which may be state dependent, and the company is free to diversify its capital assets. The basis for the evaluation of credit risk and, thus, bond pricing is a firm-value approach, originally proposed in Merton (1974). Building on a production oriented asset pricing model we show that diversifying the capital assets enhances the borrowing ability of the company by decreasing its default risk. If risk premia, debt capacity (creditwor- 
thiness $)^{35}$ and asset value are endogenous, then the asset value of companies cannot be taken as exogenous when securities such as stocks and bonds are priced.

We also showed that the default probabilities and, thus, credit risk depends on the diversification of capital assets. This can happen in various ways depending on how the shocks to the diversified capital assets are correlated.

Using modern computational methods, we solved the intertemporal decision problem and computed the asset value for firms with endogenous risk premia. In the stochastic version with diversified capital assets, we allowed for correlated shocks to those capital assets and considered their impact on the company's value and default probability. We also explored the impact of different diversification and investment strategies.

Recent credit market events have underscored the fact that purely statistical models have an underlying weakness. That is that they may rely on parameters which are simply reported by firms and/or computed from reported data. Our model shows that it is possible to relate some aspects of default risk to fundamental structures within a firm. In this way, it is possible to highlight how the correlation of shocks to a firm's capital assets correlate with some aspects of a firm's credit risk and how to control it.

Obviously, our method is dependent upon adjustment costs, i.e., the ease with which a firm can shift its strategy from one productive asset to another. We are currently developing simulations to test the sensitivity of the model. Proxies for the internal "flexibility" of a firm also need to be established. These may differ by industry. For example, in the pharmaceutical industry, the "time-toapproval" may be such a proxy. In this case, the drug approval process involves so many aspects of a company's internal operations, the "time-to-approval," as compared to other similar companies, may prove to be suitable. We are also trying to develop empirical tests of the basic structure of our model. We also want to note that our study suggests the possibility of reconsidering the issue of the equity premium from the perspective of the default premium and internal hedging techniques.

Finally, we want to mention that besides the idiosyncratic causes of credit risk, there are also common causes for corporate default. These include economywide interest rate changes, relevant spreads, and general tightening of credit constraints. Thus, at best, the total picture will remain complex.

\section{References}

[1] Bardi, M. and I. Capuzzo Dolcetta (1997), "Optimal control and viscosity solutions of Hamilton-Jacobi-Bellman equations", Boston, MA: Birkhäuser.

[2] Bernanke, B., M. Gertler, and S. Gilchrist (1999), "The Financial Accelerator in a Quantitative Business Cycle Framework", in J. Taylor and

\footnotetext{
${ }^{35}$ Our above analytical study of the debt control problem and suggests some methods of how to empirically evaluate sustainable debt, see Semmler (2006, ch. 4).
} 
M. Woodford (eds), Handbook of Macroeconomics, Amsterdam, NorthHolland.

[3] Black, F. and M. Scholes (1973), "The Pricing of Options and Corporate Liabilities," Journal of Political Economy: 81, 81-98.

[4] Camilli, F., A. Cesaroni, L. Grüne, and F. Wirth Stabilization of controlled diffusions via Zubov's method. Stoch. Dyn. Stoch. Dyn., 6(2006), pp. 373394.

[5] Camilli, F. and M. Falcone An approximation scheme for the optimal control of diffusion processes. RAIRO, Modélisation Math. Anal. Numér., 29:97-122, 1995.

[6] Camilli, F., L. Grüne, and F. Wirth A regularization of Zubov's equation for robust domains of attraction. In A. Isidori, F. Lamnabhi-Lagarrigue, and W. Respondek, editors, Nonlinear Control in the Year 2000, Volume 1, Lecture Notes in Control and Information Sciences 258, pages 277-290. NCN, Springer Verlag, London, 2000.

[7] Capuzzo Dolcetta, I. (1983), On a Discrete Approximation of the HamiltonJacobi Equation of Dynamic Programming, Appl. Math. Optim., vol. 10, pp. $367-377$.

[8] Cochrane, J. (1991), "Production-Based Asset Pricing and the Link Between Stock Returns and Economic Fluctuations", Journal of Finance, 46(1), pp. 209-237.

[9] Cochrane, J. (1996), "A Cross-Sectional Test of an Investment-Based Asset Pricing Model", Journal of Political Economy, 104(3), pp. 572-621.

[10] Cochrane, J. (2000), "Asset Pricing", Princeton: Princeton University Press.

[11] Crouhy, M., D. Galai, R. Mark (2000), "A Comparative Analysis of Current Credit Risk Models," Journal of Banking \& Finance: 24, 59-117.

[12] Das, S., D. Duffie, N. Kapadia, L. Saita (2007), "Common Failings: How Corporate Defaults are Correlated," Journal of Finance, Volume 62: Issue 1, February:pp 93-117

[13] Duan, J.C., G. Gauthier, J. Simonato, S. Zaanoun (2002), Estimating Merton's Model by Maximum Likelihood with Survivorship Consideration, working paper, Rotman School of Management, University of Toronto.

[14] Duffie, D. \& K. Singleton (1997), "An Econometric Model of the Term Structure of Interest Rate Swap Yields," Journal of Finance: vol. 52, pp. $1287-1323$. 
[15] Embrechts, P., F. Lindskog, A. McNeil (2003), "Modeling Dependence with Copulas and Applications to Risk Management," in: Handbook of Heavy Tailed Distributions in Finance, ed. S. Rachev: Elsevier, Chapter 8, pp. 329-384.

[16] Falcone, M. (1987), A Numerical Approach to the Infinite Horizon Problem of Deterministic Control Theory, Appl. Math. Optim., vol. 15, pp. 1-13. Corrigenda (1991), ibid., vol. 23, 213-214.

[17] Gaskins, D.W. (1971), "Dynamic Limit Pricing: Optimal Pricing under Threat of Entry", Journal of Economic Theory 3, pp. 306-322.

[18] Gertler, M. and S. Gilchrist (1994), "Monetary Policy, Business Cycles and the Behavior of Small Scale Firms", Quarterly Journal of Economics, vol. CIX, May.

[19] Gomes, J.F., A. Yaron, and L. Zhang (2002), "Asset Pricing Implications of Firms' Financing Constraints", working paper, The Wharton School, University of Pennsylvania.

[20] Grüne, L. (1997), "An Adaptive Grid Scheme for the Discrete HamiltonJacobi-Bellman Equation", Numerische Mathematik vol. 75, pp. 9-337.

[21] Grüne, L, M. Metscher and M. Ohlberger (1999), On Numerical Algorithm and Interactive Visualization for Optimal Control Problems, Comput. Vis. Sci., vol. 1, pp. 221-229.

[22] Grüne, L. (2001), Subdivision Techniques for the Computation of Domains of Attraction and Reachable Sets, Proc. of NOLCOS 2001, St. Petersburg, Russia, pp. $762-767$.

[23] Grüne, L. (2002), Asymptotic Behavior of Dynamical and Control Systems under Perturbation and Discretization, Lecture Notes in Mathematics, Springer Verlag, to appear.

[24] Grüne, L. (2005), Error estimation and adaptive discretization for the discrete stochastic Hamilton-Jacobi-Bellman Equation, Numerische Mathematik, 99:85-112, 2005.

[25] Grüne, L., W. Semmler and M. Sieveking (2004), "Creditworthiness and Thresholds in a Credit Market Model with Multiple Equilibria", Journal of Economic Theory, vol 25, no 2: 287-315.

[26] Grüne, L. and W. Semmler (2003), "Solving Asset Pricing Models with Stochastic Dynamic Programming", paper prepared for the conference of the Society of Computational Economics, Seattle, July 2003, CEM working paper, Bielefeld University.

[27] Grüne, L. and W. Semmler (2004), "Using Dynamic Programming with Adaptive Grid Scheme for Optimal Control Problems in Economics", Journal of Economic Dynamics and Control, vol 28: 2427-2456. 
[28] Grüne, L., Semmler, W. (2005), "Default Risk, Asset Pricing, and Debt Control," Journal of Financial Econometrics: vol. 3, no. 1, Winter, pp. 79-106

[29] Grüne, L. and W. Semmler (2007), "Asset Pricing-Constraint by Past Consumption Decisions", Journal of Computational Economics, vol 29, no 3-4: pp 233-265.

[30] Hanke, M. (2003), "Credit Risk, Capital Structure and the Pricing of Equity Options", Heidelberg and New York, Springer Publishing House.

[31] Hull, J. \& A. White, (2000), "Valuing Credit Default Swaps I: No Counterparty Default Risk," Journal of Derivatives: Vol. 8, No. 1, Fall pp. 29-40

[32] Hull, J. \& A. White, (2001), "Valuing Credit Default Swaps II: Modeling Default Correlations," Journal of Derivatives, Vol. 8, No. 3, Spring, pp. 12-22

[33] Jonkhart, M. (1979), "On the term structure of interest rates and the risk of default: An analytical approach," Journal of Banking \& Finance: Volume 3, Issue 3, September, pp.253-262.

[34] Judd, K. and B. Petersen (1986), "Dynamic Limit Pricing and Internal Finance", Journal of Economic Theory 39, pp. 368-399.

[35] Keynes, J.M. (1967), The General theory of Employment, Interest and Money. London, Macmillan.

[36] P. E. Kloeden and E. Platen. Numerical Solution of Stochastic Differential Equations. Springer-Verlag, Heidelberg, 1992. (3rd revised and updated printing, 1999).

[37] Lucas, Douglas J. (1995), "Default Correlation and Credit Analysis," The Journal of Fixed Income: March, pp. 76-87

[38] Madan, D. \& H. Unal, (1998), "Pricing the Risks of Default," Review of Derivatives Research: 2, 121-60.

[39] Modigliani, F. and M. H. Miller, (1958), "The Cost of Capital, Corporation Finance and the Theory of Investment," American Economic Review: $48(3), 261-297$

[40] Merton, R.C. (1974), "On the Pricing of Corporate Debt: The Risk Structure of Interest Rates", Journal of Finance, 2: 449-470.

[41] Miller, M. and J. Stiglitz (1999), Bankruptcy Protection against Macroeconomic Shocks, mimeo, The World Bank.

[42] Schönbucher, P. (2001), "Factor Models: Portfolio Credit Risk When Defaults are Correlated," The Journal of Risk Finance: Vol. 3 (1), Fall), pp. 45-56. 
[43] Semmler, W. (2006), "Asset Prices, Booms and Recessions", Heidelberg/New York, Springer Publishing House, 2nd ed.

[44] Tobin, J. (1969), A General Equilibirum Approach to Monetary Theory, Journal of Money, Credit and Banking 1, (1) 15-29.

[45] Townsend, R. (1979), "Optimal Contracts and Competitive Markets with Costly State Verification", Journal of Economic Theory, 21: 265-293. 